\title{
Microgram per Hour
}

National Cancer Institute

\section{Source}

National Cancer Institute. Microgram per Hour. NCI Thesaurus. Code C67394.

A unit of mass flow rate equivalent to the rate at which one millionth of a gram of matter crosses a given surface or is delivered to a given object or space over a period of time equal to one hour. 